Endocrinol. Japon. 1962, 9 (2), 93 102

\title{
EFFEGTS OF SOME ANABOLIC STEROIDS ON THE GROWTH IN MALE AND FEMALE RATS
}

\section{TOMOKO FUJII, YOSHIKO MORITA AND RYOSHU KOYAMA}

\author{
Department of Pharmacology, Tokyo Wom?n's Medical College, Tokyo
}

Previously one of the authors reported that the growth of male rats was inhibited by methylandrostenediol (MAD), when it was given in the immaturc period, whereas the growth of female was accelerated (Fujii, 1959a). The same results were obtained with testosterone propionate (TP) (Fujii, 1959b).

These phenomena would be reasonably explained on the basis that an cxcessive dose of androgen may cause the growth retardation in male rats.

The present paper is concerned with the effects upon the rat growth of 19nortestosterone phenylpropionate (19-Nor) and 4-chlorotestosterone acetate (4-Cl), which have less androgenic and more anabolic effects than TP (Hershberger et al., 1953; Hosoi et al., 1958; Kawana et al., 1959).

\section{MATERIALS AND METHODS}

Sixteen male and 16 female rats of Wistar-King A strain inbred in this Department were used.

Ten $\mathrm{mg} / \mathrm{kg}$ of $19-\mathrm{Nor}, 4-\mathrm{Gl}$ and $\mathrm{TP}$ in saline suspension, $10 \mathrm{mg}$ per cc, were subcutaneously administered every other day in weekdays from 7 to 100 days of age. The control rats were given saline subcutaneously.

All animals were weaned at the 21 st day after birth, fed with the compressed diet (Oriental Co.) and water ad libitum. They were kept at a temperature of $23 \pm 2^{\circ} \mathrm{C}$ and at a humidity of $55 \pm 5 \%$.

The body weight was measured once a week.

On the 100th day after birth, the rats were sacrificed hy decapitation and organs were excised. Smaller organs were weighed with torsion balance up to $0.1 \mathrm{mg}$ and larger ones with usual balance up to $0.1 \mathrm{~g}$. Desoxyribonucleic acid (DNA) and ribonucleic acid (RNA) of the liver, thymus, testis, prostate and uterus were extracted according to the method of Schmidt, Tanhauser and Schneider (1946), and DNA was determined colorimetrically with the diphenylamine reagent (Dishe and Schwarz, 1937), RNA with the orcinol reagent (Brown, 1946). Glutamic pyruvic transaminase (GPT) activity in the liver was colorimetrically determined by the procedure described elsewhere (Morita and Kamei, 1962). Xanthine oxidase activity in the liver was manometrically measured with the pyrophosphate buffer (Dhungat and Sreenivasan, 1954). Total nitrogen determination of the liver, thigh muscle, uterus and serum was made by a modified micro-Kjeldahl procedure (Matsumura, 1955).

\section{RESULTS}

\section{Body weight}

The growth of male rats was depressed in every group continuously treated with TP, 19-Nor or 4- Cl as compared with controls. The growth retardation in

Received for publication April 2, 1962. 


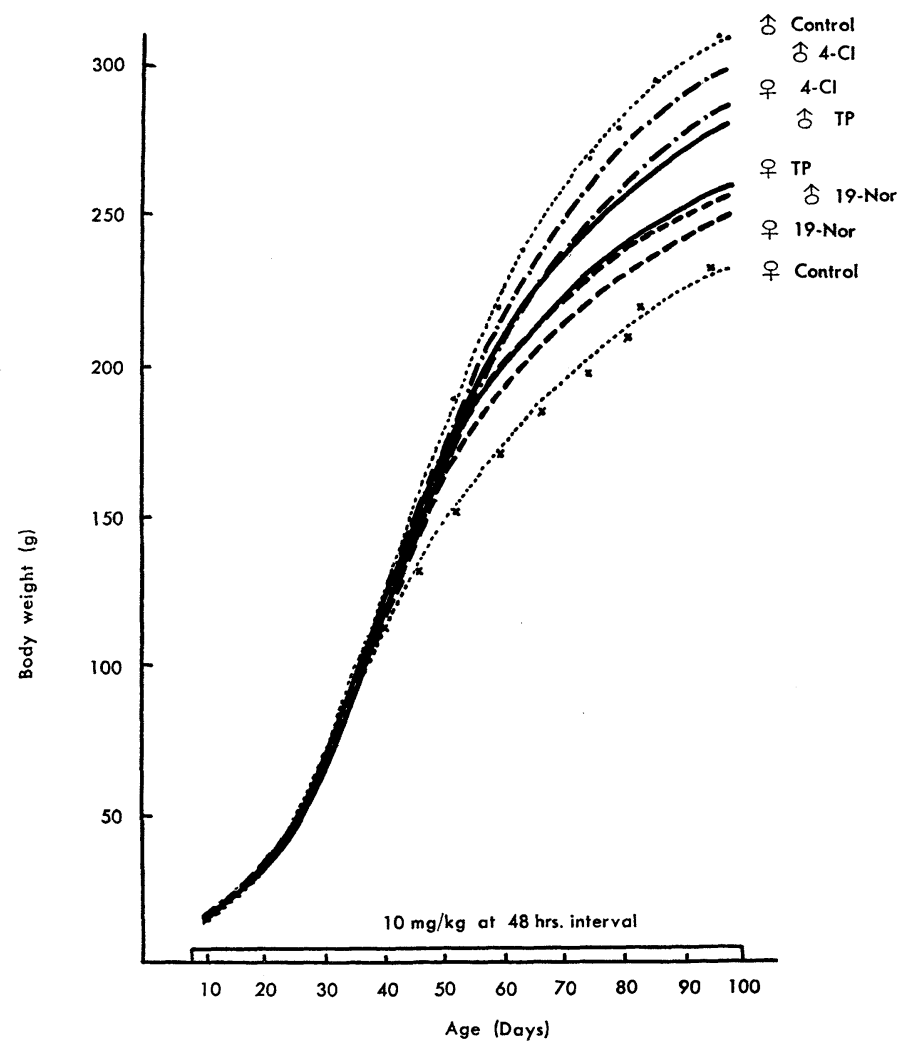

Fig. 1. Body weight curves of rats in normal and treated with TP, 19-Nor or 4-Cl Each group consists of 4 animals in this figure and the followings.

Table $i$. The various organ weights of rats in

\begin{tabular}{lrccccrr}
\hline \hline Treatment & $\begin{array}{c}\text { No. } \\
\text { of } \\
\text { rat }\end{array}$ & Liver & Kidney & Spleen & Heart & $\begin{array}{r}\text { Submax. } \\
\text { gland }\end{array}$ & \multicolumn{1}{c}{$\begin{array}{c}\text { Levator } \\
\text { ani }\end{array}$} \\
\hline Control & 4 & $3174 \pm 212 *$ & $538 \pm 65$ & $172 \pm 9$ & $308 \pm 16$ & $158 \pm 15$ & $85.8 \pm 9.0$ \\
77 TP & 4 & $3312 \pm 120$ & $651 \pm 90$ & $176 \pm 9$ & $356 \pm 21$ & $197 \pm 12$ & $95.8 \pm 7.7$ \\
19-Nor & 4 & $3229 \pm 133$ & $771 \pm 26$ & $177 \pm 12$ & $354 \pm 22$ & $212 \pm 7$ & $101.6 \pm 9.1$ \\
$4-\mathrm{Cl}$ & 4 & $3018 \pm 182$ & $701 \pm 20$ & $161 \pm 9$ & $322 \pm 12$ & $174 \pm 9$ & $84.4 \pm 6.0$ \\
\hline Control & 4 & $3654 \pm 143$ & $686 \pm 12$ & $222 \pm 9$ & $326 \pm 10$ & $185 \pm 10$ & \\
우 TP & 4 & $3432 \pm 152$ & $715 \pm 78$ & $184 \pm 14$ & $337 \pm 15$ & $162 \pm 17$ & \\
19-Nor & 4 & $3318 \pm 31$ & $877 \pm 63$ & $202 \pm 18$ & $330 \pm 2$ & $213 \pm 13$ & \\
$4-\mathrm{Cl}$ & 4 & $3297 \pm 48$ & $780 \pm 47$ & $152 \pm 13$ & $314 \pm 7$ & $196 \pm 5$ & \\
\hline
\end{tabular}

The weights of the liver, kidney, spleen, submaxillary gland and heart were expressed in terms of the weight per $100 \mathrm{~g}$ body weight and the others in the absolute weight. 


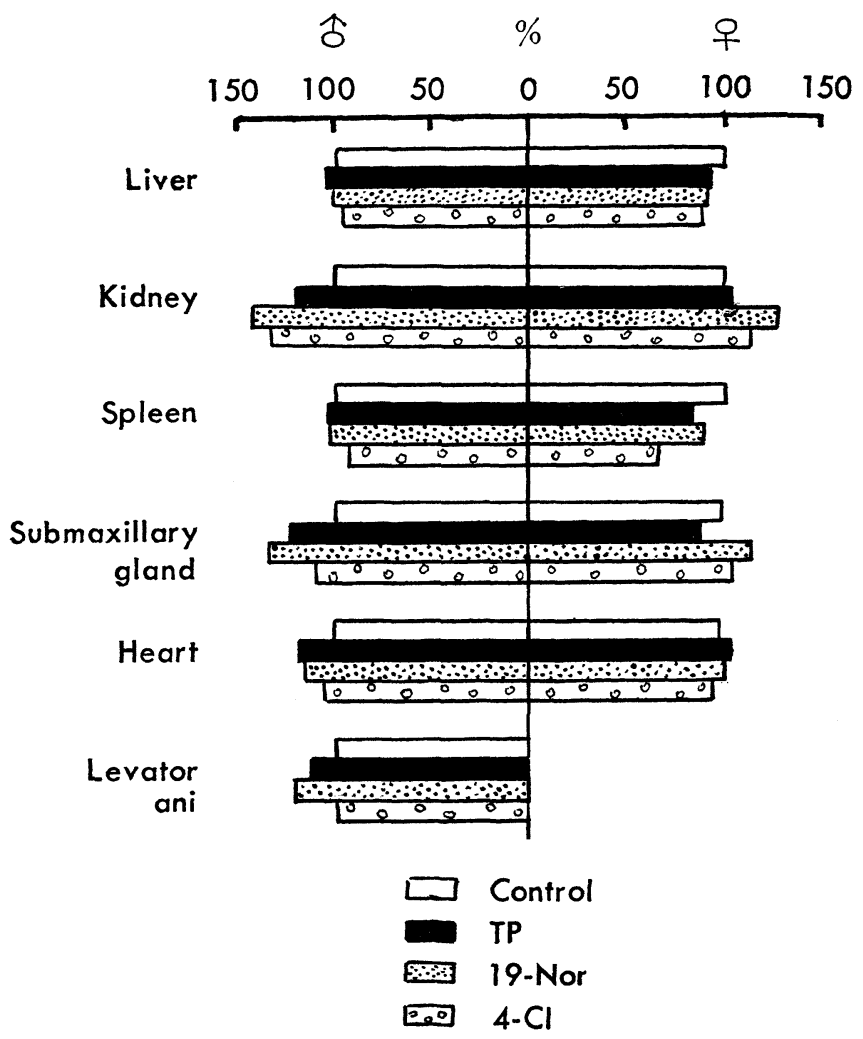

Fig. 2. Comparison of the various organ weights of rats in normal and treated with TP, 19-Nor or $4-\mathrm{Cl}$

These organ weights were expressed in terms of weight per $100 \mathrm{~g}$ body weight.

normal and treated with TP, 19-Nor and 4-Cl

\begin{tabular}{rccccccc}
\hline \hline Thymus & Thyroid & Adrenal & $\begin{array}{c}\text { Testis } \\
\text { or } \\
\text { Ovary }\end{array}$ & $\begin{array}{c}\text { Seminal } \\
\text { vesicle } \\
\text { or } \\
\text { uterus }\end{array}$ & Prostate & $\begin{array}{c}\text { Preputial } \\
\text { gland }\end{array}$ & $\begin{array}{c}\text { Pituitary } \\
\text { gland }\end{array}$ \\
\hline $214 \pm 17$ & $23.8 \pm 1.4$ & $40.4 \pm 1.6$ & $2895 \pm 161$ & $798 \pm 43$ & $384 \pm 30$ & $115 \pm 12$ & $8.9 \pm 0.5$ \\
$174 \pm 23$ & $22.2 \pm 1.6$ & $35.6 \pm 3.4$ & $1440 \pm 68$ & $868 \pm 124$ & $510 \pm 23$ & $112 \pm 12$ & $6.4 \pm 0.3$ \\
$76 \pm 11$ & $19.1 \pm 2.7$ & $40.6 \pm 0.7$ & $2395 \pm 70$ & $758 \pm 97$ & $328 \pm 50$ & $138 \pm 17$ & $6.5 \pm 0.5$ \\
$150 \pm 22$ & $23.3 \pm 2.1$ & $36.6 \pm 5.3$ & $1252 \pm 102$ & $576 \pm 25$ & $321 \pm 35$ & $111 \pm 10$ & $6.8 \pm 0.2$ \\
\hline $279 \pm 25$ & $26.5 \pm 1.4$ & $72.1 \pm 4.0$ & $84.9 \pm 3.8$ & $396 \pm 49$ & & $108 \pm 13$ & $12.0 \pm 1.3$ \\
$182 \pm 25$ & $23.1 \pm 1.1$ & $55.5 \pm 5.3$ & $54.6 \pm 15.0$ & $382 \pm 47$ & & $172 \pm 18$ & $5.3 \pm 1.1$ \\
$58 \pm 13$ & $21.5 \pm 1.7$ & $41.2 \pm 3.0$ & $11.9 \pm 5.1$ & $406 \pm 15$ & & $231 \pm 23$ & $5.7 \pm 0.4$ \\
$127 \pm 4$ & $23.1 \pm 3.0$ & $38.6 \pm 6.5$ & $21.6 \pm 2.2$ & $353 \pm 9$ & & $154 \pm 23$ & $7.0 \pm 0.4$ \\
\hline
\end{tabular}

* Standard error 


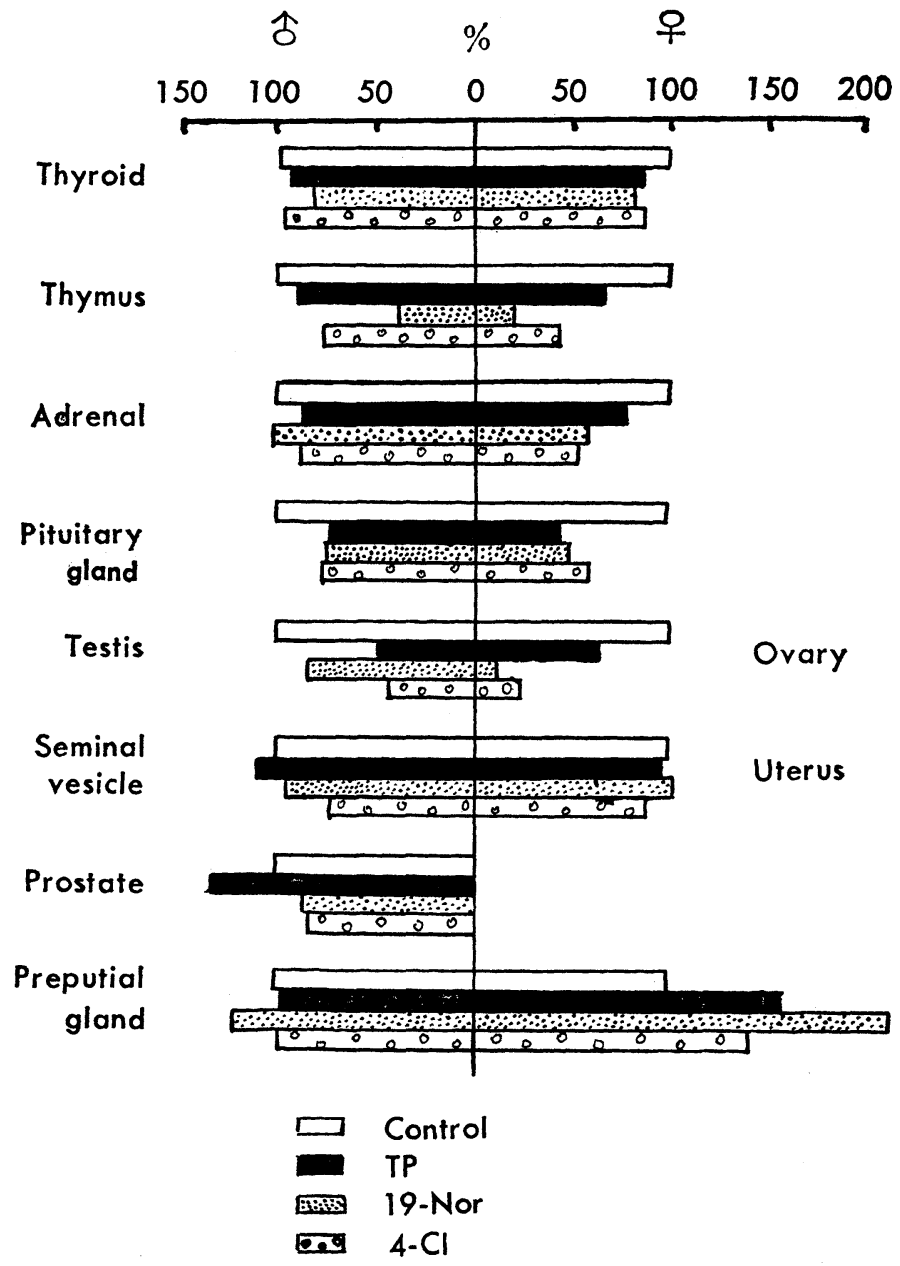

Fig. 3. Comparison of the various organ weights of rats in normal and treated with TP, 19-Nor or $4-\mathrm{Cl}$

These organ weights were expressed as absolute weight.

male rats was conspicuous, especially in the 19-Nor-treated group. On the contrary, the females showed an increase in the body weight after 19-Nor, TP and more markedly, 4-Gl treatment (Fig. 1).

\section{Organ weight}

On the basis of the results obtaincd previously in a detailed study of the relationship between organ weight and body weight (unpublished data), the weight of the organs examincd here were expressed as relative weight or absolute weight.

The weights of the liver, kidney, spleen, submaxillary gland, heart and levator ani were expressed in terms of weight per $100 \mathrm{~g}$ body weight and those of 


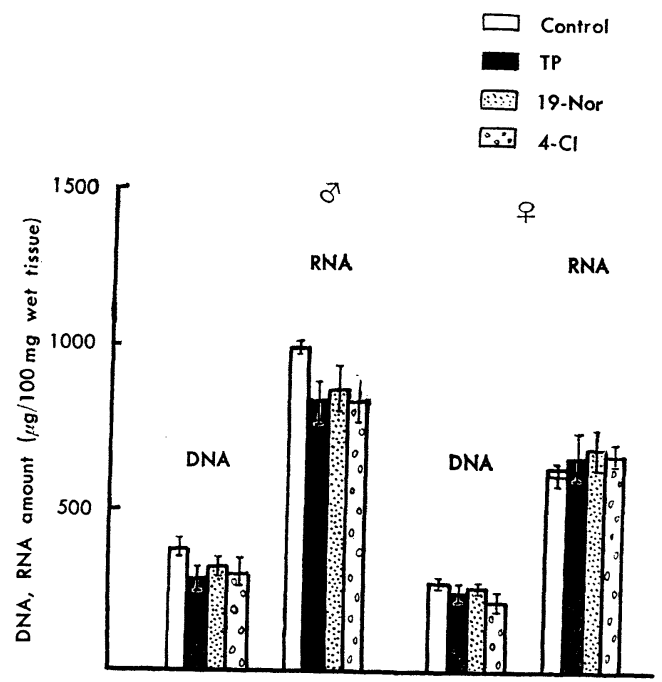

Fig. 4. DNA and RNA contents in the liver of rats in normal and treated with TP, 19-Nor or 4-Cl

Standard deviation is shown by vertical line.

the thyroid, thymus, adrenal, pituitary gland, testis, ovary, prostate, seminal vesicle, uterus and preputial gland in absolute weight (Figs. 2 and 3). The kidney weight was increased by TP, 19-Nor or 4-Cl treatment. A marked decrease in weight was observed in the thymus and pituitary gland of both sexes, testis, ovary and female's adrenal. Changes in weight of the thymus and pituitary gland were more marked in females than in males of every group. The effects of TP on the reproductive and accessory reproductive organs were essentially same as those obtained in the previous investigation; a decrease in the testis weight and an increase in the accessory reproductive organ weight were obvious, whereas the groups reccived 19-Nor or 4-Gl administration showed a decrease in weight of both organs. As to the ovarian weight, 19-Nor or 4-Cl caused more significant depression than TP.

\section{Nucleic acid content}

RNA content per unit weight of the liver (Fig. 4) in the male rats received TP, 19-Nor or 4-Cl was far lower than that of intact controls, whereas the RNA content in the female rats seemed to be increased. DNA concentration in the liver showed a slight decrease in both sexes. The thymus DNA content (Fig. 5) was diminished by TP, 19-Nor or 4-Cl administration in only male rats. Both DNA and RNA contents in the testis after TP or 4-Cl were found to be increased. A marked decrease was observed in the amount of uterus DNA in all groups treated with these three steroids (Fig. 6).

\section{Total nitrogen amount}

In spite of the changes in nucleic acids concentration in the liver and uterus, 


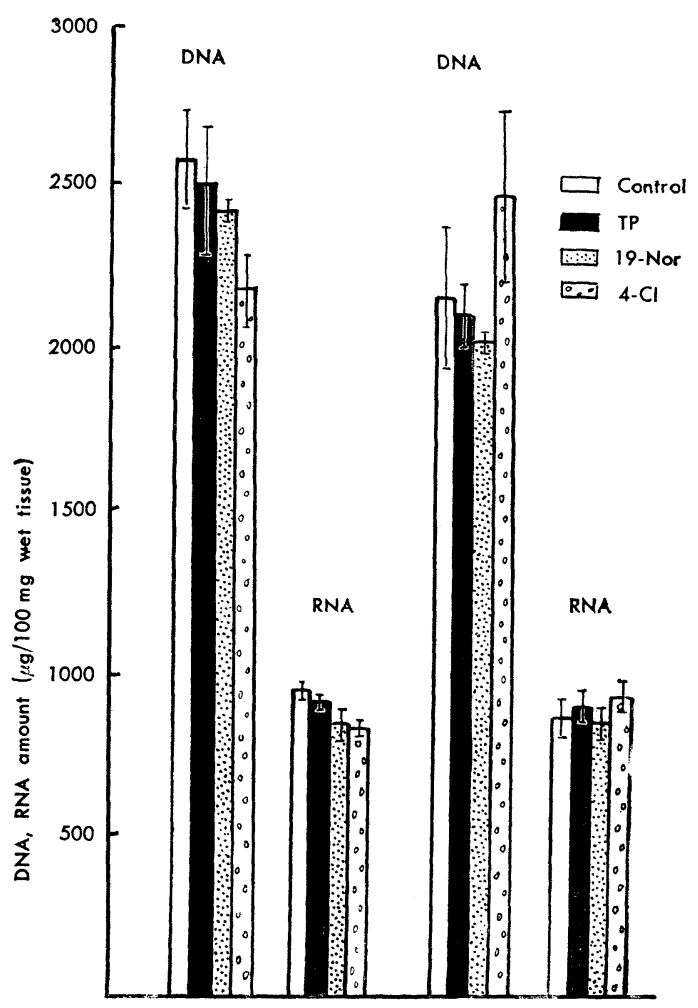

Fig. 5. DNA and RNA contents in the thymus of rats in normal and treated with TP, 19-Nor or $4-\mathrm{Cl}$

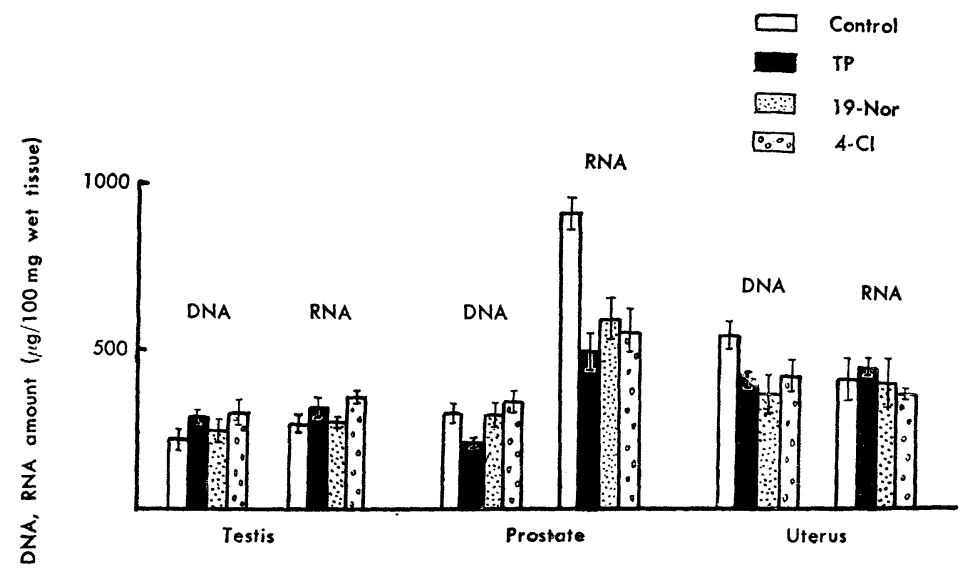

Fig. 6. DNA and RNA contents in the testis, prostate and uterus of rats in normal and treated with TP, 19-Nor or $4-\mathrm{Cl}$ 
the total nitrogen concentration per unit weight of those organs was almost the same as that of control animals (Table 2). Total nitrogen value in the thigh muscle and serum was also found to be within normal range.

Table 2. Total nitrogen amount in the liver, thigh muscle, uterus and serum of rats in normal and treated with TP, 19-Nor and 4-Cl

\begin{tabular}{|c|c|c|c|c|c|c|}
\hline & \multirow{2}{*}{ Treatment } & \multirow{2}{*}{$\begin{array}{l}\text { No. } \\
\text { of } \\
\text { rat }\end{array}$} & \multicolumn{2}{|c|}{ Liver } & \multicolumn{2}{|c|}{ Muscle } \\
\hline & & & $0^{7}$ & 오 & $0^{7}$ & 우 \\
\hline \multirow{6}{*}{$\begin{array}{l}\mathrm{mg} / \mathrm{g} \\
\text { wet } \\
\text { tissue }\end{array}$} & Control & 4 & $35.1 \pm 1.0^{*}$ & $34.6 \pm 0.6$ & $35.4 \pm 0.8$ & $37.1 \pm 0.9$ \\
\hline & TP & 4 & $35.7 \pm 1.0$ & $36.2 \pm 1.4$ & $35.8 \pm 1.0$ & $36.2 \pm 0.6$ \\
\hline & 19-Nor & 4 & $36.2 \pm 0.8$ & $35.8 \pm 1.3$ & $34.6 \pm 0.6$ & $36.6 \pm 0.4$ \\
\hline & $4-\mathrm{Cl}$ & 4 & $36.1 \pm 1.0$ & $35.6 \pm 0.4$ & $34.9 \pm 1.4$ & $35.3 \pm 0.4$ \\
\hline & \multirow{2}{*}{ Treatment } & \multirow{2}{*}{$\begin{array}{l}\text { No. } \\
\text { of } \\
\text { rat }\end{array}$} & Uterus & \multicolumn{3}{|c|}{ Serum $\mathrm{g} / \mathrm{d} l$} \\
\hline & & & & $\sigma^{7}$ & \multicolumn{2}{|c|}{ 오 } \\
\hline \multirow{4}{*}{$\begin{array}{l}\mathrm{mg} / \mathrm{g} \\
\text { wet } \\
\text { tissue }\end{array}$} & Control & 4 & $20.7 \pm 1.4$ & $1.12 \pm 0.03$ & \multicolumn{2}{|c|}{$1.10 \pm 0.02$} \\
\hline & $\mathrm{TP}$ & 4 & $22.2 \pm 1.3$ & $1.08 \pm 0.02$ & \multicolumn{2}{|c|}{$1.06 \pm 0.01$} \\
\hline & 19-Nor & 4 & $21.7 \pm 1.8$ & $1.07 \pm 0.01$ & \multicolumn{2}{|c|}{$1.12 \pm 0.02$} \\
\hline & $4-\mathrm{Cl}$ & 4 & $23.7 \pm 1.3$ & $1.09 \pm 0.02$ & \multicolumn{2}{|c|}{$1.13 \pm 0.01$} \\
\hline
\end{tabular}

* Standard error

\section{GPT and xanthine oxidase activity}

It was observed that the GPT activity in the liver was slightly decreased in male rats and was considerably increased in female rats by the respective administration of these steroids. The same effects were found on the xanthine oxidase activity (Table 3).

Table 3. GPT and xanthine oxidase activity in the liver after TP, 19-Nor and 4-Cl

\begin{tabular}{|c|c|c|c|c|c|}
\hline & $\begin{array}{c}\text { No. of } \\
\text { rat }\end{array}$ & Control & TP & 19-Nor & $4-\mathrm{Cl}$ \\
\hline GPT & $0^{7} 4$ & $4.45 \pm 0.58^{*}$ & $4.06 \pm 0.10$ & $4.29 \pm 0.10$ & $4.12 \pm 0.56$ \\
\hline $\mathrm{m} M / \mathrm{hr} / \mathrm{g}$ liver & 우 4 & $2.54 \pm 0.18$ & $3.33 \pm 0.26$ & $3.18 \pm 0.20$ & $3.73 \pm 0.70$ \\
\hline Xanthine oxidase & $0^{2} 4$ & $5.61 \pm 0.74$ & $4.89 \pm 2.48$ & $5.64 \pm 0.92$ & $5.58 \pm 0.63$ \\
\hline $\mathrm{QO}_{2}$ & 우 4 & $5.68 \pm 0.54$ & $5.99 \pm 0.39$ & $6.11 \pm 0.07$ & $5.77 \pm 0.62$ \\
\hline
\end{tabular}

* Standard error

\section{DISCUSSION}

It was reconfirmed that there was retardation of the growth in male rats received continuous $\mathrm{TP}$ administration, in contrast with growth acceleration in female rats. Unexpectedly, the administration of $19-$ Nor or 4-Cl which was known 
as a potent anabolic steroid resulted the tendency similar to $\mathrm{TP}$ administration, though the response of various organs to these three steroids were different to some extent; the weight of the accessory reproductive organs were increased by $\mathrm{TP}$, and conversely it was significantly decreased by 19-Nor or 4-Cl. The testis weight was reduced by all these steroids, but less markedly by $19-$ Nor.

It is interesting that both sexes following these three steroids showed a decrease in weight of the thymus, pituitary gland and reproductive organs, particulary in females, although there was an increase in the body weight in this sex. Considering the inhibiting effect of androgenic steroids to the pituitary gland (Dorfman, 1956; Miyake, 1961), different effects among these steroids on various organs seem to be exerted through the actions upon the pituitary-hypothalamic system. It is difficult, however, to draw a conclusion concerning the direct or indirect action from the data of organ weight.

Androgenic steroids play a major role in stimulating body growth and in inducing a positive nitrogen balance, and anabolic steroid administration is associated with an increase in body weight. These effects have been observed in the male animals (Rinne and Näätänen, 1958; Kawana et al., 1959). However, the experiments on the growth promoting action of various steroids have generally been performed by using the castrated or hypophysectomized animals, and in the intact animals these experiments have been done only on the short term basis. Discrepancy of the results between the present experiment and those by others may be partially explained by the differences in the duration of treatment or the age of animals, although sex difference in the growth observed in the present experiment should be elucidated by further studies.

It is always difficult to establish whether or not a steroid, being myotrophic with the levator ani test (Eisenberg and Gordan, 1950), is protein anabolic on the whole body, even though the levator ani muscle is widely considered as a possible endpoint for measuring protein anabolism (Hershberger et al., 1959; Ando and Kobayashi, 1961). In this experiment levator ani weight showed no appreciable changes after the administration of the steroids; no increase in weight which may suggest the anabolic action, nor decrease in weight, catabolic action. Serizawa and Yoshizaki (1961) reported that the uterus in castrated rats could be an indicator of the anabolic action of various steroids as well as the levator ani in males. Uterine weight in this study, however, did not show any remarkable changes. It is unlikely that any of these organs serves as a satisfactory criterion for the anabolic effect under the conditions of chronic study with intact animals.

Upon analyzing the hormonal influence on the growth in terms of body weight change, it should be considered that the similar changes possibly take place through various mechanisms. The results obtained here also propose a number of hypotheses as an explanation for the body wcight reduction in males or an increase in females. For examples, in female rats, the body weight increase might be induced by the direct anabolic effect of exogenous androgen or by the obesity associated with reduced general function due to the deficiency of endogenous estrogen caused by the treatment or by other mechanisms.

The ability of endogenous androgen to exhibit the sex difference in the growth response to $\mathrm{TP}, 19-\mathrm{Nor}$ or $4-\mathrm{Cl}$ may be considered, but the present results 
can not be explained by only the androgen level in animals, since 19-Nor, supposed to be less androgenic than TP or approximately equal to 4-Cl caused most conspicuous depression of the growth in male rats.

Reports indicating sex difference in the metabolism of corticosteroids have been published by Yates et al. (1958) and Glenister and Yates (1961). The authors assume that there may be sex difference in the metabolism of androgenic steroids, and studies to ascertain this assumption are now in progress.

At present, possible alternative explanation is as follows: The difference in the body weight change between male and female after steroid treatment in this experiment may be attributed to the different metabolism between sexes, e.g., as exemplified by a decrease in RNA content per unit weight of the liver in males, and an increase in females. Moreover, GPT and xanthine oxidase activity of the liver homogenate showed a decrease in males and an increase in females. Further works are required to obtain more precise information on the mechanism of these steroids on the growth in connection with age and sex.

\section{SUMMARY}

The continuous administration of $10 \mathrm{mg} / \mathrm{kg}$ of 19-nortestosterone phenylpropionate (19-Nor), 4-chlorotestosterone acetate (4-Cl) and testosterone propionate (TP) from 7 to 100 days of age at $48 \mathrm{hrs}$. intervals, produced a decrease in the rate of growth in male and an increase in female rats.

A decisive decrease in weight of the thymus and pituitary gland of both sexes and in female's adrenal was observed after all three steroids, especially in female rats. A decrease in weight of the testis and ovary, and an increase in weight of the seminal vesicle and prostate were observed by TP administration. In the groups received 19-Nor or 4-Cl, however, was found a decrease in weight of those organs.

The liver of the treated male rats contained less amount of RNA than that of control animals, whereas RNA concentration in females became somewhat higher than that of controls. Total nitrogen amount in the liver, thigh muscle, uterus and serum remained essentially unchanged after those treatment.

Sex difference in the metabolic state was induced by these steroids, 19-Nor, 4- $\mathrm{Cl}$ and TP, as evidenced by the facts that the concentration of RNA and the activity of GPT and xanthine oxidase in the liver exhibited an increase in female and a decrease in male rats.

\section{ACKNOWLEDGMENTS}

The authors are indebted to Teikoku Hormone Mfg. Co., Ltd. for supplies of testosterone propionate and 4-chlorotestosterone acetate and to Sankyo Co. Ltd. for 19-nortestosterone phenylpropionate. 


\section{REFERENCES}

Ando, H. and O. Kobayashi (1961). Clinical Endocrinology 9, 247. (In Japanese)

Brown, A.H. (1946). Arch. Biochem. 11, 269.

Dhungat, S.B. and A. Sreenivasan (1945). J. Biol. Chem. 208, 845.

Dishe, Z. and K. Schwarz (1937). Mikrochim. Acta 2, 13.

Dorfman, R.I. Androgens. John Wiley and Sons Inc., N.Y., p. 89 (1956).

Eisenberg, E. and G.S. Gordan (1950). J. Pharmacol. Exptl. Therap. 99, 38.

Fujii, T. (1959a). Endocrinol. Japon. 6, 47.

Fujii, T. (1959b). Ibid. 6, 125.

Glenister, D.W. and F.E. Yates (1961). Endcrinology 68, 747.

Hershberger, L.G., G. Shipley and R.K. Meyer (1953). Proc. Soc. Exptl. Biol. Med. 83, 175.

Hosoi, M., Y. Yanada, A. Kambegawa and O. Kobayashi (1958). Folia Endocrinol. Japon, 34, 679.

Kawana, T., K. Koike, Y. Takagi and J. Kikuchi (1959). Clinical Endocrinology 7, 981. (In Japanese)

Matsumura, Y. (1955). Clinical Pathology 3, 50. (In Japanese)

Miyake, T. (1961). Endocrinology 69, 534.

Morita, Y. and T. Kamei (1962). Endocrinol. Japon. 9, 361.

Rinne, U.K. and E.K. Näätänen (1958). Acta Endocrinol. 27, 415.

Schneider, W.C. (1946). J. Biol. Chem. 164, 747.

Serizawa, J. and T. Yoshizaki (1961). Annual of Takamine Lab. 13, 154. (In Japanese)

Yates, F.E., A.L. Herbst and J. Urquhart (1958). Endocrinology 63, 887. 